\title{
Desenvolvendo a criatividade em alunos com e sem Altas Habilidades/Superdotação através de suplementação em língua inglesa
}

\author{
Developing creativity in gifted and non-gifted students through English \\ language supplementation
}

Desarrollo de la creatividad en estudiantes con y sin altas habilidades mediante suplementación del idioma inglés

\section{* Taís Crema Remoli Ferreira}

Doutoranda pela Universidade Estadual Paulista Júlio de Mesquita Filho, São Paulo, São Paulo, Brasil. taiscrema@hotmail.com - http://orcid.org/0000-0001-5279-7718

\section{** Vera Lucia Messias Fialho Capellini}

Professora doutora na Universidade Estadual Paulista Júlio de Mesquita Filho, São Paulo, São Paulo, Brasil. vera.capellini@unesp.br

Recebido em 08 de janeiro de 2019

Aprovado em 08 de abril de 2019

Publicado em 12 de setembro de 2019

\section{RESUMO}

Atualmente no Brasil, são poucos os alunos identificados com Altas Habilidades/Superdotação (AH/SD) e ainda mais problemática é a oferta de atividades de enriquecimento a tal público a partir de áreas de seu interesse. Por isto, optou-se por realizar um programa de suplementação para crianças com AH/SD que demonstraram interesse em aprender língua inglesa. Tal programa foi elaborado com o objetivo de desenvolver não apenas o idioma, mas também a criatividade dos participantes. Alunos sem AH/SD e com as mesmas características do primeiro grupo ingressaram no projeto, totalizando 12 participantes, seis meninos e seis meninas. O trabalho foi realizado durante o segundo semestre de 2015, tendo como objetivos verificar o desenvolvimento da criatividade antes e após o programa de suplementação e comparar o desempenho dos grupos a fim de analisar a intervenção realizada. Para a obtenção dos dados, foram realizados dez encontros destinados à intervenção e outros dois para aplicação do Teste de Criatividade Figural Infantil (TCFI). Os resultados evidenciaram que o programa de intervenção desenvolveu três fatores, dos cinco avaliados pelo teste, com significância estatística na comparação geral dos alunos: Enriquecimento de ideias, aspectos cognitivos e Fator geral - havendo diferença entre os fatores ao se analisar os resultados por grupos com e sem AH/SD. Observou-se, deste modo, que oportunizar um ambiente enriquecedor beneficiou, de formas diferentes, o desenvolvimento da criatividade de todos os envolvidos no processo. 
Palavras-chave: Altas Habilidades/Superdotação; Criatividade; Língua inglesa.

\section{ABSTRACT}

Currently in Brazil, there are only few students identified with giftedness and even more problematic is offering enrichment activities to this public related to areas of their interest. Therefore, it was decided to carry out a supplementation program for gifted children who showed interest in learning English. This program was created with the objective of developing not only language but also the creativity of the participants. Non-gifted students with the same characteristics of the first group enrolled the project, totaling 12 participants, six boys and six girls. The research was carried out during the second semester of 2015 aiming to verify the development of creativity before and after the supplementation program and to compare the performance of the groups in order to analyze the intervention. Data was obtained through ten meetings of intervention and two for the creativity test (Teste de Criatividade Figural Infantil - TCFI). The results showed that the intervention program developed three of the five factors evaluated by the test, with statistical significance in the general comparison of students: Enrichment of ideas, Cognitive aspects and General Factor, with difference between the factors for gifted and non-gifted group results. Thus it was observed that providing an enriching environment benefited the development of the creativity of all those involved in the process in different ways.

Keywords: Giftedness; Creativity; English language.

\section{RESUMEN}

Actualmente en Brasil, hay pocos estudiantes identificados con Altas Habilidades y aún más problemática es la oferta de actividades de enriquecimiento para ese público en áreas de interés. Por esta razón, se decidió llevar a cabo un programa de suplementación para niños con Altas Habilidades que mostraron interés en aprender inglés. Este programa fue diseñado para desarrollar no solo el lenguaje sino también la creatividad de los participantes. Estudiantes sin Altas Habilidades y con las mismas características del primer grupo se unieron al proyecto, totalizando 12 participantes, seis niños y seis niñas. El trabajo se llevó a cabo durante el segundo semestre de 2015, con el objetivo de verificar el desarrollo de la creatividad antes y después del programa de suplementación y comparar el desempeño de los grupos para analizar la intervención realizada. Para obtener los datos, se realizaron diez reuniones para la intervención y otras dos para aplicar la prueba de creatividad(Teste de Criatividade Figural Infantil - TCFI). Los resultados mostraron que el programa de intervención desarrolló tres factores, de los cinco evaluados por la prueba, con significación estadística en la comparación general de los estudiantes: Enriquecimiento de ideas, aspectos cognitivos y Factor general, con una diferencia entre los factores al analizar los resultados por grupos con y sin Altas Habilidades. Así, se observó que proporcionar un ambiente enriquecedor benefició, de diferentes maneras, el desarrollo de la creatividad de todos los involucrados en el proceso.

Palabras clave: Altas Habilidades; Creatividad; Idioma en Inglés. 


\section{Introdução}

O conceito de pessoas com Altas Habilidades/Superdotação (AH/SD), proposto pela Política Nacional de Educação Especial na Perspectiva da Educação Inclusiva (BRASIL, 2008), caracteriza-se pelo potencial elevado em qualquer dos seguintes aspectos, isolados ou combinados: capacidade intelectual, aptidão acadêmica, capacidade de liderança, talento especial para as artes e capacidade psicomotora, envolvimento com aprendizagem e tarefas de seu interesse e grande criatividade.

Crianças com essas características extrapolam o ensino que lhes é ofertado, tendo imaginação frutífera e aguçada (PISKE, STOLTZ; CAMARGO, 2016, p. 207), assim, os países que investirem em indivíduos com $\mathrm{AH} / \mathrm{SD}$ no século $\mathrm{XXI}$ provavelmente continuarão à frente dos demais, visto que aprendem mais rapidamente que seus pares, são mais capazes em termos de criatividade, arte e liderança, demonstram capacidade acadêmica especial, entendem ideias abstratas e exibem altos níveis de desempenho (SATMAZ; GENCEL, 2018).

De acordo com Renzulli e Reis (1997), embora nenhum critério possa ser usado para determinar $\mathrm{AH} / \mathrm{SD}$, pessoas que obtiveram reconhecimento por suas conquistas únicas e contribuições criativas possuem os três seguintes traços interlaçados: habilidade acima da média, comprometimento com a tarefa e criatividade, e cada um deles apresenta importante contribuição. No entanto, Renzulli (2018) salienta que enquanto a inteligência geral, as aptidões específicas e a realização acadêmica tendem a permanecer relativamente constantes com o passar dos anos, a criatividade e o compromisso com a tarefa são contextuais, situacionais e temporais.

O autor aponta ainda que crianças que são capazes de desenvolver uma interação entre os três traços citados necessitam de uma variedade de oportunidades educacionais, recursos e encorajamento além dos que são normalmente providos por programas regulares de instrução, por isto é grande a importância de programas de atendimento a esse público (RENZULLI, 2014).

Sabe-se que, não apenas no Brasil, como internacionalmente, a temática das AH/SD tem suscitado um interesse crescente em pesquisadores (ANTIPOFF; CAMPOS, 2010) e diferentes autores corroboram a visão de que a criatividade é uma das principais características deste construto (ALMEIDA; CAPELLINI, 2005; FREEMAN, 2016; SATMAZ; GENCEL, 2018). Assim, um grande desafio aos que trabalham com esse público, 
http://dx.doi.org/10.5902/1984686X39344

especialmente aos educadores, é criar condições para transformar o potencial de seus alunos, especialmente porque

\begin{abstract}
Estimular a criatividade envolve não apenas estimular o indivíduo, mas também afetar seu meio social e as pessoas que nele vivem. Se aqueles que circundam a pessoa não valorizam a criatividade, não oferecem o ambiente de apoio necessário, não aceitam o trabalho criativo quando este é realizado, então é provável que os esforços criativos do indivíduo encontrem obstáculos sérios se não intransponíveis. (STEIN, 1974, epígrafe).
\end{abstract}

Por meio da visão desse importante estudioso da temática, nota-se o quão relevante são o estímulo e a valorização da criatividade a fim de se transformar pessoas e o ambiente em que vivem. No entanto, embora as habilidades criativas possam ser educáveis e desenvolvidas (MERCEDES et al, 2015), ainda há poucos trabalhos, entre teses e dissertações brasileiras, que abordam a interação entre criatividade e AH/SD (ZAVITOSKI, 2015), embora sejam construtos relacionados.

Uma das pesquisas brasileiras realizadas com programa de criatividade foi a de Wechsler (1987), que comparou um grupo composto por estudantes de $4^{\circ}$ e $5^{\circ}$ anos, com e sem AH/SD após treinamento de criatividade (intervenção com 23 sessões de duas horas) e um grupo controle que não passou pelo treinamento. Como resultados, obteve-se ganho em criatividade e desempenho escolar para ambos os grupos, com os alunos com AH/SD superando os outros quanto à participação; porém, com maiores ganhos para alunos sem $\mathrm{AH} / \mathrm{SD}$ em relação à fluência figural, originalidade figural, fluência verbal e motivação.

Outra pesquisa que também comparou a criatividade em grupos de alunos com e sem AH/SD foi a de Gonçalves (2010), utilizando o Teste Torrance de Pensamento Criativo para avaliar 48 alunos de $6^{\circ}$ ano. Como resultado, foram observados maiores escores nos fatores originalidade verbal e figurativa no grupo de alunos com $\mathrm{AH} / \mathrm{SD}$, mas sem diferenças nos grupos quanto à fluência verbal e figurativa e flexibilidade verbal e figurativa.

Analisando mais a fundo a relação das AH/SD com a criatividade, Machado e Stolz (2017) pesquisaram uma sala de recursos do Paraná e perceberam que a arte e a criatividade constituíam-se como instrumentos capazes de auxiliar estudantes com AH/SD a compreenderem seu mundo interior, possibilitando-Ihes oportunidades para o emprego do potencial criativo e inovador. Nesse sentido, o estudo aponta para a necessidade de revisão das práticas pedagógicas destinadas a esses discentes, bem como para a investigação de metodologias de ensino que integrem as atividades artísticas e criativas em suas práticas educacionais. Com o mesmo foco, alguns estudos de Freeman (2016) 
abordaram os conflitos de jovens com AH/SD e seu alto nível de criatividade, visto que seus traços de personalidade, como a coragem de agir, acabam sendo influenciados pelo conforto da aprovação social, o que pode inibir seu pensamento criativo devido à pressão.

A fim de compreender melhor a relação entre criatividade e AH/SD, Remoli e Capellini (2017) realizaram uma revisão de literatura de artigos publicados entre 2005 e 2015 a partir dos dois descritores nas bases de dados Web of Science e Dialnet, obtendo 20 artigos que abordavam algum tipo de conexão entre os termos em questão, os quais foram classificados em estudos teóricos (4), revisão de literatura (4) e estudos experimentais (12). Foi observado predomínio de temáticas relacionadas à comparação da criatividade em alunos com e AH/SD (especialmente com crianças do Ensino Fundamental como públicoalvo), tendo como objetivo, no entanto, apenas medir a criatividade.

Não foram encontrados estudos empíricos a respeito de programas de criatividade para alunos com AH/SD (REMOLI; CAPELLINI, 2017), confirmando os resultados de Zavitoski (2015) e de Matthews (2015) quanto à falta de publicações a respeito de criatividade em programas voltados para alunos com AH/SD e a necessidade de novos estudos que verifiquem quais oportunidades estão sendo oferecidas atualmente e sua aplicabilidade para essa população.

Nesse sentido, Alencar (2015) ressalta que estímulos, circunstâncias e oportunidades proporcionadas pelo ambiente podem favorecer ou inibir a expressão criativa. De acordo com Mendonça e Fleith (2005), uma maneira de se desenvolver a criatividade é a proficiência em uma segunda língua, verificada por meio de seu trabalho realizado com adolescentes e adultos brasileiros bilíngues, os quais apresentaram escores superiores nas medidas de criatividade verbal e figurativa que seus pares monolíngues. $\mathrm{O}$ mesmo foi comprovado por Lee e Kim (2011), os quais avaliaram 114 estudantes bilíngues (coreano/inglês) por meio do Teste Torrance de Pensamento Criativo, indicando que o grau do bilinguismo se correlacionava positivamente com a criatividade independentemente de sexo ou idade.

Quanto às AH/SD e o ensino de línguas, em uma busca realizada na base de dados Web of Science, em 2018, utilizando-se os descritores "giftedness" e "second language", apenas três artigos foram obtidos: a revisão de literatura de Kitano e Espinosa (1995) com foco em falantes de uma segunda língua com AH/SD nos Estados Unidos, destacando que eles possuem maior proficiência linguística, bagagem cultural, tipo e nível de talento; a 
pesquisa de Baser e Kanar (2014), ressaltando que crianças com AH/SD aprendem uma segunda língua mais rapidamente, especialmente as que apresentam habilidades linguísticas avançadas, possuindo compreensão antecipada, elaboração de perguntas incomuns e de sentenças longas, por isto recomendam que familiares e professores estejam atentos a esse público; e o artigo mais recente, de Biedrón e Pawlak (2016), o qual constatou que alunos com AH/SD são frequentemente negligenciados no ensino de um segundo idioma.

Embora crianças com AH/SD tendam a adquirir uma segunda língua mais rapidamente (IOWA, 2008), pesquisas nesta área ainda são escassas, fato observado por meio de consultas ao banco de dados da CAPES em 2015 e 2016, revelando que produções a respeito do desenvolvimento da criatividade por meio do ensino de línguas a alunos com AH/SD ainda eram inexistes (REMOLI, 2017).

Partindo desses princípios, optou-se por realizar um trabalho a partir de um programa de suplementação realizado com língua inglesa, objetivando-se avaliar a criatividade de alunos com e sem AH/SD antes e depois desse programa.

\section{Método}

\section{Participantes}

Alunos previamente identificados e confirmados com AH/SD por Mendonça (2015) e que por meio de questionário realizado pela pesquisadora demonstraram interesse no aprendizado da língua inglesa - foram convidados e aceitaram participar da pesquisa, a qual contou com seis participantes, três meninas e três meninos, de 7 a 10 anos, do $2^{\circ}$ ao $5^{\circ}$ ano. Após 0 aceite desse grupo, a escola na qual os alunos estudavam auxiliou na seleção de outros seis alunos sem AH/SD - também de acordo com a pesquisa de Mendonça (2015) - com o objetivo de estabelecer um grupo homogêneo às características básicas do grupo com AH/SD quanto ao sexo, à idade e ao ano escolar. A Tabela 1 apresenta maiores detalhamentos dos dois grupos. 
http://dx.doi.org/10.5902/1984686X39344

Tabela 1 - Caracterização dos grupos com e sem AS/DH ${ }^{1}$

\begin{tabular}{|c|c|c|c|}
\hline ALUNO & SEXO & IDADE (EM ANOS) & ANO ESCOLAR \\
\hline 1 & $\mathrm{~F}$ & 7 & $2^{\circ}$ \\
\hline 2 & $\mathrm{~F}$ & 7 & $2^{0}$ \\
\hline 3 & M & 7 & $2^{0}$ \\
\hline 4 & M & 7 & $2^{0}$ \\
\hline 5 & $\mathrm{~F}$ & 9 & $4^{\circ}$ \\
\hline 6 & $\mathrm{~F}$ & 9 & $4^{\circ}$ \\
\hline 7 & M & 9 & $4^{\circ}$ \\
\hline 8 & M & 9 & $4^{\circ}$ \\
\hline 9 & M & 9 & 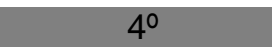 \\
\hline 10 & M & 9 & $4^{\circ}$ \\
\hline 11 & $\mathrm{~F}$ & 10 & $5^{0}$ \\
\hline 12 & $\mathrm{~F}$ & 10 & $5^{\circ}$ \\
\hline
\end{tabular}

\section{Local}

Fonte: adaptada de Remoli (2017).

A pesquisa foi realizada em uma cidade de médio porte do interior do estado de São Paulo. A escola estadual na qual os alunos estudavam foi o local escolhido para o desenvolvimento do programa de intervenção a fim de facilitar o deslocamento dos participantes, que residiam no mesmo bairro da instituição de ensino. Os espaços destinados às atividades foram os cedidos pela própria escola: sala de aula, sala de informática e pátio.

\section{Intervenção}

O grupo composto por doze crianças participou simultaneamente do programa de desenvolvimento da criatividade por meio de suplementação em língua inglesa, com encontros semanais de duas horas diárias, após o período de aulas regulares, durante 0 segundo semestre de 2015, compondo um total de dez encontros destinados às intervenções. Outros dois momentos destinaram-se à explicação do projeto aos alunos e seus familiares (antes do programa de intervenção) e dois à aplicação de testes, de forma coletiva, de língua inglesa e criatividade (antes e após o programa de intervenção), cujos dados serão apresentados neste estudo.

O programa de intervenção contou com grande parte dos encontros organizados em três momentos:

1- - Warm up: "aquecimento", visando um início de encontro de forma motivadora e divertida, retomando conteúdos da aula anterior, como por meio de música, diálogo em inglês, jogo de memória com imagens e vocabulário estudado etc.

\footnotetext{
1 *Alunos indicados com a faixa cinza são os que compõem o grupo com $\mathrm{AH} / \mathrm{SD}$, seguidos por seus pares sem $\mathrm{AH} / \mathrm{SD}$, nas faixas brancas.
} 
http://dx.doi.org/10.5902/1984686X39344

2ํ - Ensino formal: focado no conteúdo programático a ser trabalhado, que foi elaborado pela pesquisadora a partir de objetivos voltados a alunos de Ensino Fundamental 1. Foram utilizadas imagens, atividades impressas, leitura de diferentes tipologias textuais, prática escrita e oral, atividades de fixação de conteúdo etc.

$3^{\circ}$ - Elaboração de produto final: prática do conteúdo aprendido por meio da utilização de diferentes materiais, tendo como objetivo elaborar histórias em quadrinhos, máscaras, quadros representando rotinas, autorretrato/autodescrição etc. Neste momento, os alunos recebiam a instrução do produto final a ser elaborado, mas ficavam livres para explorar os materiais disponíveis e criar.

O programa de intervenção foi previamente elaborado de forma flexível; por isto, sofreu modificações ao longo do curso devido ao ritmo de aprendizado de seus alunos, tendo como formato final o conteúdo exposto no Quadro 1:

Quadro 1 - Cronograma do programa de intervenção

\begin{tabular}{|c|c|c|}
\hline AULA & CONTEÚDO & ATIVIDADES \\
\hline 1 & Autoapresentação & $\begin{array}{l}\text { Leitura de história em quadrinhos com temática de conversas } \\
\text { introdutórias em inglês (trabalhando o conteúdo sobre como se } \\
\text { apresentar para algum desconhecido). Atividades de fixação no } \\
\text { caderno. Criação de parágrafo introdutório sobre si. Prática oral } \\
\text { em duplas. }\end{array}$ \\
\hline 2 & Apresentação & $\begin{array}{l}\text { Elaboração de diálogo coletivo (cumprimentos). Atividades } \\
\text { relacionadas a características pessoais e partes do corpo. } \\
\text { Música sobre partes do corpo (Head, shoulders, knees and toes) } \\
\text { e jogo da memória de características físicas, utilizando } \\
\text { terminologia em inglês. }\end{array}$ \\
\hline 3 & Sentimentos & $\begin{array}{l}\text { Jogo da memória para retomar vocabulário da aula anterior. } \\
\text { Atividade coletiva com expressões de sentimentos. Criação de } \\
\text { diálogo coletivo sobre o tema, ensaio e apresentação oral. } \\
\text { Elaboração de história em quadrinhos utilizando os elementos } \\
\text { aprendidos. }\end{array}$ \\
\hline 4 & Animais / cores & $\begin{array}{l}\text { Música Head, shoulders, knees and toes para iniciar a aula e } \\
\text { auxiliar a fixação da nomenclatura relacionada às partes do } \\
\text { corpo. Atividade impressa relacionada ao tema em estudo. } \\
\text { Fixação de vocabulário por meio da criação de animais de } \\
\text { massinha e apresentação oral das criações. }\end{array}$ \\
\hline 5 & Animais / cores & $\begin{array}{l}\text { Prática oral de vocabulário estudado em pequenos grupos. } \\
\text { Música Roar para ser completada a partir de termos conhecidos. } \\
\text { Criação de animal coletivo em lousa para exploração do } \\
\text { vocabulário relacionado a partes do corpo de animais. }\end{array}$ \\
\hline 6 & $\begin{array}{l}\text { Números e revisão de } \\
\text { conteúdo }\end{array}$ & $\begin{array}{l}\text { Atividade oral para introdução aos números a partir de } \\
\text { conhecimento prévio dos alunos e registro. Atividade de fixação } \\
\text { e prática por meio de jogos de computadores, previamente } \\
\text { selecionados pela professora. }\end{array}$ \\
\hline 7 & $\begin{array}{l}\text { Revisão de conteúdo / } \\
\text { paisagem }\end{array}$ & $\begin{array}{l}\text { Diálogo com perguntas pessoais praticado em duplas. Atividade } \\
\text { impressa sobre paisagens para trabalho com descrições. } \\
\text { Construção de cenário coletivo em lousa, revisando a } \\
\text { nomenclatura aprendida. }\end{array}$ \\
\hline
\end{tabular}


Conclusão

\begin{tabular}{|l|lr|l|}
\hline 8 & $\begin{array}{l}\text { Prática de "linstening" } \\
\text { e paisagem }\end{array}$ & $\begin{array}{l}\text { Música para alunos completarem com vocabulário conhecido. } \\
\text { Atividade impressa para relacionar paisagem e nomenclatura. } \\
\text { Criação e explicação dos elementos da paisagem criada, } \\
\text { individualmente, com tinta guache. }\end{array}$ \\
\hline 9 & $\begin{array}{l}\text { Revisão } \\
\text { autoapresentação de } \\
\text { rotinas }\end{array}$ & $\begin{array}{l}\text { Apresentação da atividade de casa This is me (autorretrato), } \\
\text { utilizando frases aprendidas para descrever o desenho criado a } \\
\text { as preferências inseridas. Introdução ao tema "rotina diária" com } \\
\text { atividades orais e no caderno. Elaboração de desenhos em } \\
\text { lousa representando rotinas. }\end{array}$ \\
\hline 10 & Revisão / rotinas & $\begin{array}{l}\text { Elaboração e apresentação individual de história em quadrinhos } \\
\text { com diálogos aprendidos ao longo do curso. Criação e partilha } \\
\text { de cenas de rotinas diárias utilizando recortes de revistas e } \\
\text { vocabulário aprendido. }\end{array}$ \\
\hline
\end{tabular}

Fonte: adaptado de Remoli (2017).

\section{Instrumento}

Para avaliar a criatividade dos participantes, utilizou-se o Teste de Criatividade Figural Infantil - TCFI, elaborado por Nakano, Wechsler e Primi (2011) a partir do Torrance Test of Creative Thinking, que é validado no Brasil para alunos do segundo ao nono ano do Ensino Fundamental. A correção do teste descrito permite a obtenção de pontuações em quatro fatores, avaliando-se o Enriquecimento de ideias (Fator 1) - habilidade de ver coisas sob diferentes perspectivas e pontos de vista, a Emotividade (Fator 2) - expressão da essência de uma ideia por meio da abstração, a Preparação criativa (Fator 3) - habilidade para selecionar a melhor ideia como solução ao problema apresentado utilizando recursos que a completem ou enriqueçam e os Aspectos cognitivos (Fator 4) - habilidade de considerar fatores importantes envolvidos em um problema e procurar as soluções que possam produzir os resultados mais satisfatórios. Há, ainda, uma pontuação total, denominada Fator Geral, que corresponde à soma dos quatro fatores. O escore total e os escores de cada fator são convertidos em resultados padronizados e percentis, possibilitando a comparação e a classificação em inferior, abaixo da média, média, acima da média e superior em cada um dos fatores e no fator geral (NAKANO; WECHSLER; PRIMI, 2011).

Procedimento de análise dos dados

\section{Procedimento de análise dos dados}

A análise estatística foi realizada a partir das instruções para categorização do instrumento utilizado, cujos dados foram submetidos a análises por meio do BioEstat versão 5.3. Foram utilizados os testes não paramétricos Wilcoxon e Mann-Whitney, com nível de significância de $5 \%$. 


\section{Resultados e Discussão}

Após a realização dos dez encontros do programa de suplementação através da língua inglesa, os dados de pré e pós-teste foram corrigidos às cegas por dois juízes e seus escores foram interpretados. Destaca-se que o Teste de Criatividade Figural Infantil (TCFI) possibilita a interpretação dos dados de acordo com a escolarização (ano escolar e tipo de escola) dos participantes por meio da tabela de conversão para percentil - a qual permite a classificação dos resultados da seguinte maneira: alunos que pontuam abaixo de 20 possuem escores inferiores, entre 20 e 34 estão abaixo da média, a média é estabelecida entre 35 e 65, escores entre 65 e 80 são considerados acima da média e resultados acima de 81, superiores (NAKANO; WECHSLER; PRIMI, 2011). A partir de tal instrução, o resultado obtido foi tabulado, conforme apresentado no Quadro 2.

Quadro 2 - Resultado de pré e pós-teste do TCFI por fatores ${ }^{2}$

\begin{tabular}{|c|c|c|c|c|c|c|c|c|c|c|}
\hline \multirow[b]{2}{*}{ ALUNO } & \multicolumn{2}{|c|}{ FATOR 1} & \multicolumn{2}{|c|}{ FATOR 2} & \multicolumn{2}{|c|}{ FATOR 3} & \multicolumn{2}{|c|}{ FATOR 4} & \multicolumn{2}{|c|}{ FATOR } \\
\hline & PRÉ & PÓS & PRÉ & PÓS & PRÉ & PÓS & PRÉ & PÓS & PRÉ & PÓS \\
\hline 1 & Sup. & Med. & Med. & Ab.M. & Ab.M. & Inf. & Med. & Med. & Ac.M. & Med. \\
\hline 2 & Med. & Sup. & Ab.M. & Sup. & Med. & Sup. & Ac.M. & Ab.M. & Med. & Sup. \\
\hline 3 & Med. & Sup. & Ab.M. & Sup. & Med. & Med. & Med. & Ac.M. & Med. & Sup. \\
\hline 4 & Inf. & Ac.M. & Ab.M. & Sup. & Inf. & Med. & Sup. & Sup. & Med. & Sup. \\
\hline 5 & Sup. & Med. & Sup. & Sup. & Sup. & Med. & Ac.M. & Sup. & Sup. & Ac.M. \\
\hline 6 & Med. & Med. & Inf. & Inf. & Inf. & Med. & Med. & Ac.M. & Ab.M. & Ac.M. \\
\hline 7 & Inf. & Inf. & Med. & Inf. & Inf. & Inf. & Med. & Med. & Inf. & Inf. \\
\hline 8 & Med. & Sup. & Sup. & Ac.M. & Sup. & Sup. & Ab.M. & Sup. & Med. & Sup. \\
\hline 9 & Inf. & Ab.M. & Inf. & Inf. & Ab.M. & Med. & Ab.M. & Med. & Inf. & Ab.M. \\
\hline 10 & Med. & Sup. & Inf. & Inf. & Med. & Ac.M. & Ab.M. & Med. & Med. & Ac.M. \\
\hline 11 & Med. & Sup. & Ac.M. & Inf. & Med. & Ab.M. & Sup. & Sup. & Ac.M. & Sup. \\
\hline 12 & Ac.M. & Ac.M. & Med. & Inf. & Ac.M. & Med. & Ac.M. & Ac.M. & Ac.M. & Ac.M. \\
\hline
\end{tabular}

Verificando-se os resultados obtidos por meio de escores e convertidos em percentis pelos alunos com AH/SD (Alunos 1, 3, 5, 7, 9 e 11), nota-se que no Fator 1, dois alunos tiveram escores mais altos no pós-teste, três mais baixos e um se manteve o mesmo. Nos Fatores 2 e 3, dois participantes apresentaram aumento, três redução e dois mantiveram o mesmo. No fator 4, três alunos apresentaram aumento, nenhum teve diminuição e três se mantiveram iguais. Em relação ao grupo de alunos sem AH/SD (composto pelos Alunos 2, 4, 6, 8, 10 e 12), nota-se que no Fator 1 quatro alunos apresentaram melhora e dois se mantiveram os mesmos, no Fator 2, dois

\footnotetext{
${ }^{2}$ Alunos indicados com a faixa cinza são os que compõem o grupo com AH/SD, seguidos por seus pares sem AH/SD, nas faixas brancas. Legenda para tabela: Ab.M. = abaixo da média, Ac.M. = acima da média, Inf. = inferior, Med. = média, Sup. = superior.
} 
alunos apresentaram aumento, dois diminuição e dois se mantiveram iguais, no Fator 3, cinco apresentaram maiores percentis e um se manteve o mesmo e, no Fator 4, três alunos apresentaram progresso, um diminuiu seu percentil e 2 mantiveram os mesmos resultados.

Ao avaliar-se o Fator Geral, obtido a partir dos demais, nota-se que no Grupo com AH/SD, dos seis alunos, três apresentaram melhores resultados no pós-teste (Alunos 3, 9 e 11), 1 se manteve igual (Aluno 7) e 2 apresentaram escores mais baixos (Alunos 1 e 5). No Grupo sem AH/SD, apenas um participante se manteve igual (Aluno 12) e os demais apresentaram percentis mais altos (Alunos 2, 4, 6, 8 e 10). Ressaltase que, nesse fator, todos os alunos desse grupo apresentaram resultados Acima da Média ou Superiores.

A fim de facilitar a visualização por grupos, a interpretação dos resultados dos fatores e dos participantes foi agrupada em pré e pós-testes, conforme exemplificado nos Gráficos 1 e 2.

Gráfico 1 - Comparação entre as interpretações dos escores de pré e pós-teste de criatividade figural (TCFI) de alunos com AH/SD em todos os fatores

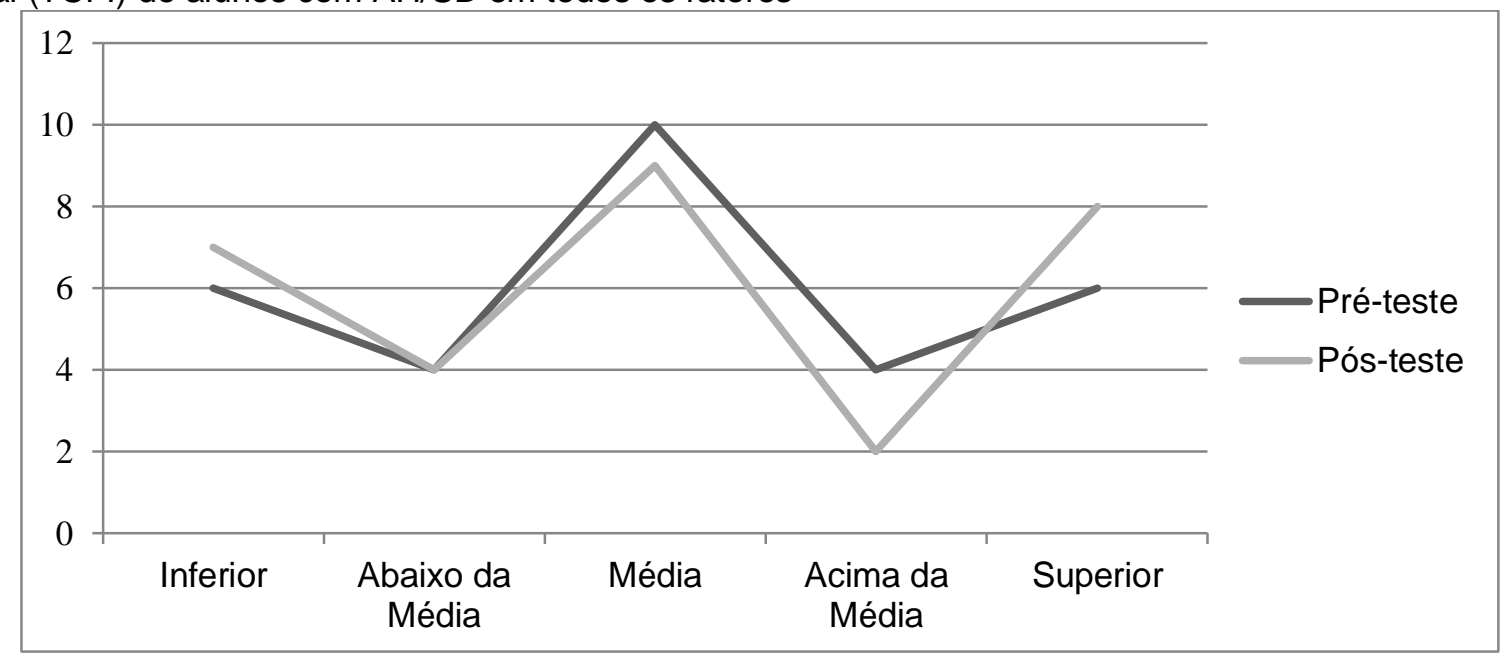

Fonte: Remoli (2017).

Por meio dos dados do Gráfico 1, nota-se que mais alunos com AH/SD pontuaram nos níveis inferior e superior no pós-teste. O número de resultados abaixo da média do grupo se manteve o mesmo, havendo, no entanto, menos resultados na média ou acima da média. Tais dados são diversos aos do grupo sem AH/SD, conforme representado no Gráfico 2. 
Gráfico 2 - Comparação entre as interpretações dos escores de pré e pós-teste de criatividade figural (TCFI) de alunos sem AH/SD em todos os fatores

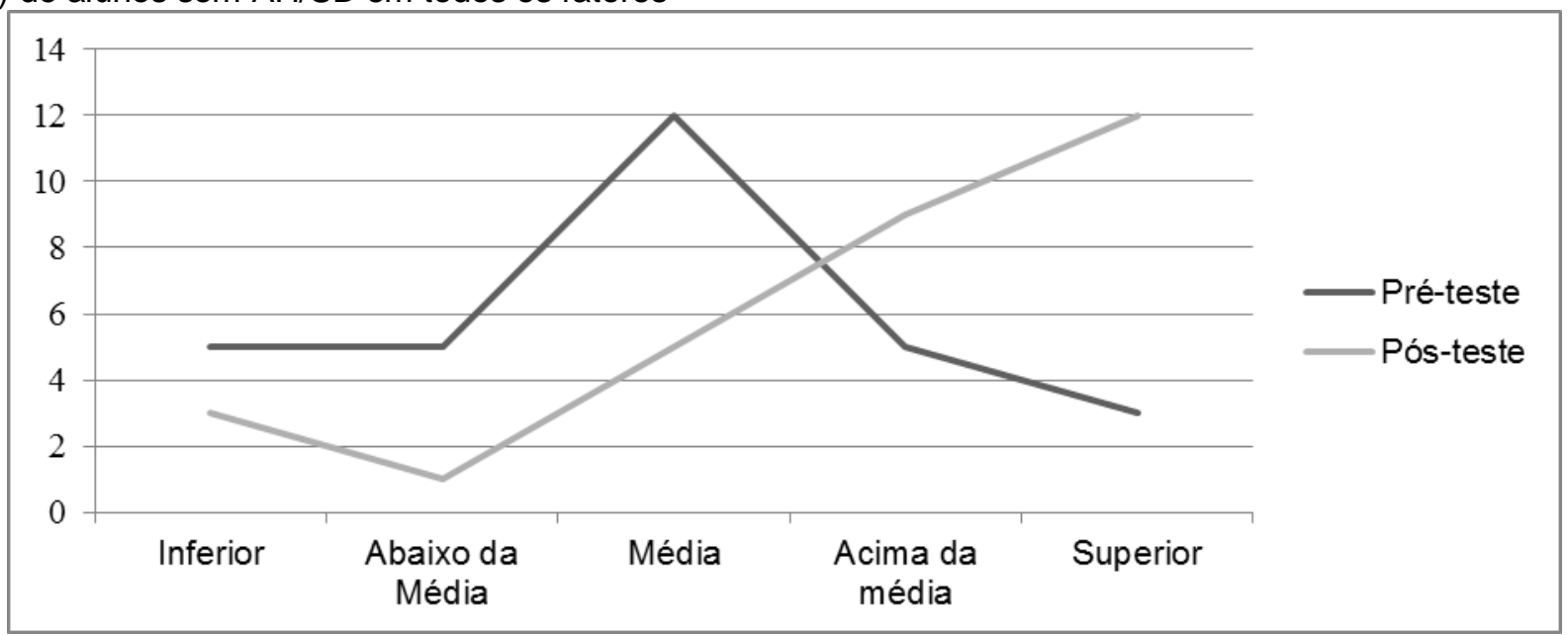

Fonte: Remoli (2017).

Verifica-se, por meio da representação do Gráfico 2, que houve diminuição dos escores inferior, abaixo da média e média para os alunos sem AH/SD e aumento nos escores acima da média e superior, conforme demonstrado no Quadro 2, o que aponta a ampliação da criatividade figural para este grupo, indicando que o programa de intervenção, por meio da avaliação das interpretações dos escores, se mostrou mais eficiente no aumento da criatividade dos alunos sem AH/SD, corroborando os dados obtidos por Wechsler (1987). No entanto, ressalta-se que outro ponto destacado pela autora foi comprovado nesta pesquisa: a maior participação dos alunos com AH/SD durante as aulas.

É importante salientar que, de acordo com Wechsler (1998), o construto em avaliação deve ser compreendido como um modelo multidimensional, ou seja, existem diversos tipos de criatividade, o que significa que cada indivíduo possui talentos específicos que poderão levar a manifestações criativas em situações variadas e que podem ser expressas de modo distinto (NAKANO; WECHSLER; PRIMI, 2011). Portanto, em uma visão de modelo multidimensional da criatividade, é preciso enfatizar que o TCFI avalia apenas a criatividade figural, não excluindo a possibilidade de o indivíduo ser criativo em outros aspectos ou em apenas algum dos fatores.

Por isto, a fim de aprofundar a compreensão dos dados obtidos, análises estatísticas com os escores dos participantes foram realizadas. Primeiramente, optou-se por verificar o resultado de todo o grupo, dos doze participantes, comparando-se pré e pós-teste, conforme apresentado na Tabela 2. 
http://dx.doi.org/10.5902/1984686X39344

Tabela 2 - Comparação entre pré e pós-teste no TCFI de todos os alunos por Wilcoxon

\begin{tabular}{l|c|c|c}
\hline \multirow{2}{*}{ FATORES } & \multicolumn{2}{|c}{ MEDIANA } & \\
\hline Enriquecimento de ideias & 44,0 & 55,0 & $0,034^{*}$ \\
Emotividade & 0,5 & 0,0 & 0,674 \\
Preparação criativa & 6,0 & 7,0 & 0,406 \\
Aspectos cognitivos & 45,0 & 56,5 & $0,023^{*}$ \\
Fator geral & 100,0 & 124,0 & $0,023^{*}$ \\
\hline
\end{tabular}

Fonte: Remoli (2017).

Por meio da Tabela 2, observa-se que dentre os 5 fatores avaliados pelo teste, quatro apresentaram resultado mais elevado no pós-teste, sendo 3 deles com significância estatística (Enriquecimento de ideias, Aspectos cognitivos e Fator geral). Assim, os dados demonstram que os 10 encontros de suplementação em língua inglesa foram relevantes para o desenvolvimento da criatividade do grupo, revelando que as condições proporcionadas foram capazes de transformar o potencial do grupo em diferentes aspectos (RENZULLI, 2014) e que o ambiente, os estímulos e as circunstâncias favoreceram a expressão criativa dos participantes (ALENCAR, 2015).

Com o objetivo de avaliar mais detalhadamente os grupos com e sem AH/SD, realizouse uma comparação dos mesmos, separadamente, conforme apresentado nas Tabelas 3 e 4 respectivamente.

Tabela 3 - Comparação entre pré e pós-teste do TCFI de alunos com AH/SD por Wilcoxon

\begin{tabular}{l|c|c|c}
\hline \multicolumn{1}{c|}{ FATORES } & \multicolumn{2}{|c}{ MEDIANA } & \\
\hline Enriquecimento de ideias & 45,5 & 42,5 & 0,6 \\
Emotividade & 1,5 & 0,0 & 0,465 \\
Preparação criativa & 5,5 & 5,5 & 0,671 \\
Aspectos cognitivos & 45,0 & 52,5 & $0,027^{\star}$ \\
Fator Geral & 107,5 & 107,5 & 0,463 \\
\hline
\end{tabular}

Fonte: Remoli (2017).

Diferentemente do resultado geral, ao analisarmos apenas o grupo de alunos com $\mathrm{AH} / \mathrm{SD}$, verificamos que dois itens tiveram menor escore no pós-teste, dois se mantiveram iguais e um apresentou maior resultado, "Aspectos cognitivos", com significância estatística. Este fator pode ser relacionado com uma das características deste grupo: habilidade acima da média (RENZULLI; REIS, 1997), capacidade intelectual (BRASIL, 2008) ou capacidade acadêmica e altos níveis de desempenho (SATMAZ; GENCEL, 2018), a qual acabou sendo ainda mais desenvolvida após estímulo por meio do trabalho realizado com um segundo idioma. Tal resultado também pode nos remeter à hipótese de que crianças com AH/SD e 
alto nível de criatividade podem ter a coragem de agir e o pensamento criativo inibidos devido à necessidade de aprovação social ou à pressão da realização de testes (FREEMAN, 2016).

No entanto, ao analisarmos o resultado do grupo de alunos sem $\mathrm{AH} / \mathrm{SD}$, outros fatores foram desenvolvidos, conforme demonstrado na Tabela 4.

Tabela 4 - Comparação entre pré e pós-teste do TCFI dos alunos sem AH/SD por Wilcoxon

\begin{tabular}{l|c|c|c}
\hline \multicolumn{1}{c|}{ FATORES } & \multicolumn{2}{|c}{ MEDIANA } & \\
\hline Enriquecimento de ideias & 42,5 & 62,5 & $0,028^{*}$ \\
Emotividade & 0,0 & 1,5 & 1,000 \\
Preparação criativa & 6,0 & 8,5 & 0,141 \\
Aspectos cognitivos & 48,0 & 57,0 & 0,173 \\
Fator geral & 97,5 & 129,5 & $0,046^{*}$ \\
\hline
\end{tabular}

Fonte: Remoli (2017).

A partir da comparação entre pré e pós-teste, nota-se aumento de todos os fatores neste grupo, com dois deles apresentado significância estatística, Enriquecimento de ideias e Fator geral (calculado a partir dos demais). Observa-se, assim, que o grupo de alunos sem AH/SD beneficiou-se mais que o primeiro, confirmando os ganhos apresentados nos Gráficos 1 e 2.

Desta forma, os resultados apresentados sinalizam que o programa de língua inglesa pode contribuir para o desenvolvimento da criatividade em fatores diferentes nos grupos com e sem $\mathrm{AH} / \mathrm{SD}$, destacando-se por maior significância estatística no grupo sem $\mathrm{AH} / \mathrm{SD}$, revelando que um ambiente enriquecido é capaz de influenciar o desenvolvimento de todos os indivíduos por promover seu aprimoramento (JENSEN, 2011), o que nos faz refletir sobre a importância de práticas pedagógicas e metodologias de ensino que integrem as atividades artísticas e criativas em suas práticas educacionais (MACHADO; STOLZ, 2017).

Ao comparar os escores do TCFI dos grupos de alunos por meio de Mann-Whitney, não se obteve significância estatística para nenhum fator nos seguintes itens: pré-teste de alunos com $X$ alunos sem $A H / S D$, pré-teste de meninas com $X$ sem $A H / S D$, pré-teste de meninos com $X$ sem $A H / S D$, pós-teste de meninas com $X$ sem $A H / S D$ e pós-teste de meninos com $X$ sem AH/SD. Ou seja, nesta pesquisa, o sexo dos participantes não foi um item relevante quanto a possíveis diferenças nos resultados obtidos. Porém, um ponto apresentou significância: a comparação do pós-teste dos grupos de alunos com e sem $\mathrm{AH} / \mathrm{SD}$, como indicado na Tabela 5. 
http://dx.doi.org/10.5902/1984686X39344

Tabela 5 - Comparação entre pós-teste do TCFI dos alunos com e sem AH/SD por meio de Mann-Whitney

\begin{tabular}{l|c|c|c}
\hline \multicolumn{1}{c|}{ FATORES } & \multicolumn{2}{|c}{ MEDIANA } & \\
\hline Enriquecimento de ideias & COM AH/SD & SEM AH/SD & $\mathrm{p}$ \\
Emotividade & 45,5 & 42,5 & 0,150 \\
Preparação criativa & 1,5 & 0,0 & 0,719 \\
Aspectos cognitivos & 5,5 & 6,0 & $0,029^{*}$ \\
Fator Geral & 45,0 & 48,0 & 0,747 \\
\hline
\end{tabular}

Fonte: Remoli (2017).

Analisando os dados apresentados na Tabela 5, a média geral dos escores do grupo com AH/SD foi maior do que do outro grupo em três fatores (Enriquecimento de ideias, Emotividade e Fator Geral), sem apresentar significância estatística. Dois fatores se mostraram mais elevados no pós-teste do grupo sem AH/SD, Preparação criativa (com significância estatística) e Aspectos cognitivos (sem significância estatística), novamente ressaltando que o trabalho de suplementação com língua inglesa desenvolveu aspectos criativos diversos nos dois grupos.

Os resultados obtidos nesta pesquisa estão de acordo com Renzulli (1998a): “A rising tide lifts all ships" ${ }^{3}$, ou seja, o estímulo a um determinado grupo é capaz de se estender aos demais, beneficiando a todos os estudantes. De acordo com o autor, pilares utilizados na educação de alunos com AH/SD vêm sendo absorvidos na educação regular como modelos para melhorar o desempenho geral, ressaltando que programas especiais e 0 papel dos especialistas em enriquecimento podem e devem contribuir para a melhoria de toda a escola, por isto, todos os estudantes devem ter oportunidades para desenvolver seu pensamento de ordem superior, buscar conteúdos mais aprofundados dos que normalmente são oferecidos nos livros didáticos e realizar investigações (RENZULLI, 1998a).

Desta forma, ressalta-se a importância de não somente se promover programas de enriquecimento a alunos com $\mathrm{AH} / \mathrm{SD}$ a fim de criar condições para transformar seu potencial (RENZULLI, 2014) e suprir as lacunas do trabalho com criatividade a esse público (REMOLI; CAPELLINI, 2017), mas também promover programas de atendimento voltados a um perfil heterogêneo de alunado, promovendo a interação com pares da mesma idade e pares intelectuais (VIRGOLIM, 2014), estimulando-se não apenas indivíduos, mas também seu meio social e as pessoas que nele vivem (STEIN, 1974).

\footnotetext{
3 "Uma maré ascendente eleva todos os navios" [Tradução livre da pesquisadora].
} 
Portanto, este trabalho com alunos com e sem $\mathrm{AH} / \mathrm{SD}$, além de ter se mostrado benéfico ao primeiro grupo, que aprendeu a conviver e respeitar diferenças e o tempo do outro, também foi importante ao segundo, o qual foi pressionado para cima, mais estimulado e desafiado, produzindo e desenvolvendo-se mais. Sendo assim, considera-se que o trabalho de suplementação em língua inglesa foi benéfico ao desenvolvimento de ambos os grupos, tendo trabalhado do mesmo modo com outros aspectos tão importantes quanto à criatividade: a convivência com pessoas com características e idades diversas, o trabalho em equipe e o respeito à diferença.

\section{Considerações finais}

Ao analisar os dados obtidos pelos grupos de alunos com e sem AH/SD após os encontros de suplementação por meio da língua inglesa, observou-se que proporcionar novos estímulos foi benéfico a ambos os grupos, visto que as análises estatísticas apresentaram diferentes fatores de criatividade desenvolvidos em cada um.

Um dado importante a ser ressaltado é o de que o grupo de alunos sem AH/SD, o qual costuma ter menos oportunidade de enriquecimento, apresentou mais ganhos que o grupo com $A H / S D$, o que leva à reflexão sobre o quanto ainda é preciso se investir em novas metodologias na sala de aula comum que possam promover o desenvolvimento da criatividade de todos, bem como quão importante e enriquecedor para todos são as oportunidades de convivência com pessoas com características e idades diversas, promovendo-se o trabalho em equipe e o respeito à diferença.

Destaca-se, como possíveis limitações à pesquisa, que fatores emocionais devem ser levados em conta ao se analisar e comparar o resultado dos testes, portanto, sugere-se que novos instrumentos que avaliem a criatividade qualitativa e longitudinalmente sejam elaborados a fim de se replicar pesquisas como está e verificar se os dados obtidos por meio do instrumento utilizado se confirmam.

\section{Referências}

ALENCAR, Eunice Maria Lima Soriano de; FLEITH, Denise de Souza; BORUCHOVITCH, Everly.Criatividade no Ensino Fundamental: Fatores Inibidores e Facilitadores segundo Gestores Educacionais. Psicologia: Teoria e Pesquisa, v. 31, n. 1, p. 105-114, 2015.

ALMEIDA, Maria Amélia; CAPELLINI, Vera Lúcia Messias Fialho. Alunos talentosos: possíveis superdotados não notados. Educação (Porto Alegre), v. 1, n. 55, p. 45- 64, 2005. 
ANTIPOFF, Cecília Andrade; CAMPOS, Regina Helena de Freitas. Superdotação e seus mitos. Revista Semestral da Associação Brasileira de Psicologia Escolar e Educacional, v. 14, n. 2, p. 301-309, 2010.

BASER, C.; KANAR, Numan. How can you "Gift" to Second Language Young Learners. Procedia - Social and Behavioral Sciences, v. 136, p. 246-249, 2014.

BIEDRÓN, Cihan; PAWLAK, M. New conceptualizations of linguistic giftedness. Language Teaching, v. 49, p. 151-185, apr. 2016. 2. ed.

BRASIL. Secretaria de Educação Especial. Política nacional de educação especial na perspectiva da educação inclusiva. Brasília, DF: MEC/SEESP, 2008.

FREEMAN, Joan. Conflicts between high level academic success and creativity. Psychchologia Wychowawcza, v. 51, n. 9. p. 45-60, 2016.

GONÇALVES, Fernanda do Carmo. Estudo comparativo entre alunos superdotados e não-superdotados em relação à criatividade, inteligência e percepção de clima de sala de aula para criatividade. Dissertação (Mestrado). Universidade de Brasília, Brasília, 2010.

IOWA. Identifying gifted and talented english language learners. lowa: The Connie Belin and Jacqueline N. Blank International Center for Gifted Education and Talent Development, $2008 . \quad$ Disponível em: https://www.educateiowa.gov/sites/files/ed/documents/IdentifyGiftedTalentedELL.pdf. Acesso em: 20 jul. 2016.

JENSEN, Eric. Enriqueça seu cérebro: como maximizar o potencial de aprendizagem de todos os alunos. Porto Alegre: Artmed, 2011.

KITANO, Margie; ESPINOSA, Ruben. Language Diversity and Giftedness: Working with Gifted English Language Learners. Journal for the Education of the Gifted, v. 18, n. 3, p. 234-254, 1995.

LEE, Hangeun; KIM, Kyung Hee. Can speaking more languages enhance your creativity? Relationship between bilingualism and creative potential among Korean American students with multicultural link. Personality and Individual Differences, v. 50, n. 8, p. 1186-1190, 2011.

MACHADO, Cristiana Lopes; STOLZ, Tania. Arte, criatividade e desenvolvimento socioemocional de alunos com altas habilidades/ superdotação (AH/SD): considerações a partir de Vigotski. Revista Educação Especial, v. 30, n. 58, p. 441454, 2017.

MATTHEWS, Michael S. Creativity and leadership's role in gifted identification and programming in the USA: a pilot study. Asia Pacific Educ. Rev., v. 16, p. 247-256, 2015. 
MENDONÇA, Lurian Dionisio. Identificação de alunos com altas habilidades ou superdotação a partir de uma avaliação multimodal. Dissertação (Mestrado) Universidade Estadual Paulista. Faculdade de Ciências, Bauru, 2015.

MENDONÇA, Patrícia Vila da Costa Ferreira; FLEITH, Denise de Souza. Relação entre criatividade, inteligência e autoconceito em alunos monolíngues e bilíngües. Psicol. Esc. Educ., v. 9, n. 1, Campinas, 2005.

MERCEDES, Ferrando; PRIETO, Lola; SAINZ, Marta; FERRÁNDIZ, Carmen. Estratégias para incentivar a criatividade na educação infantil. In: MORAIS, M. F.; MIRANDA, L. C. de; WECHSLER, S. M. (Org.). Criatividade: aplicações práticas em contextos internacionais. São Paulo: Vetor, 2015. p. 155-180.

NAKANO, Tatiana de Cássia; WECHSLER, Solange Muglia; PRIMI, Ricardo. Teste de Criatividade Figural Infantil. São Paulo: Vetor, 2011.

PISKE, Fernanda Hellen Ribeiro; STOLTZ; Tania, CAMARGO, Denise de. A compreensão de Vigotski sobre a criança com altas habilidades/superdotação, genialidade e talento. In: PISK, F. H. R. et al. (Orgs.). Altas habilidades/superdotação (AH/SD) e criatividade. Identificação e atendimento. Curitiba: Juruá, 2016. p. 207-217.

REMOLI, Taís Crema. A eficácia no desenvolvimento da criatividade em alunos com e sem superdotação por meio de suplementação em língua inglesa. Dissertação (Mestrado) - Universidade Estadual Paulista. Faculdade de Ciências, Bauru, 2017.

REMOLI, Taís Crema; CAPELLINI, Vera Lúcia Messias Fialho. Relação entre criatividade e altas habilidades/superdotação: uma análise crítica das produções de 2005 a 2015. Rev. Bras. Ed. Esp., v. 23, n. 3, p.455-470, 2017.

RENZULLI, Joseph S. Reexaminando o papel da educação para superdotados e o desenvolvimento de talentos para o Século XXI: uma abordagem teórica em quatro partes. In: VIRGOLIM, A. (Org.). Altas habilidades/superdotação. Processos criativos, afetivos e desenvolvimento de potenciais. Porto: Juruá, 2018. p. 19-42.

RENZULLI, J. S. A concepção de superdotação no modelo de desenvolvimento para a promoção da produtividade criativa. In: VIRGOLIM, A. M. R.; KONKIEWITZ, E. C. (Org.). Altas habilidades/superdotação, inteligência e criatividade. Campinas: Papirus, 2014. p. 219-264.

RENZULLI, Joseph S. A rising tide lifts all ships: Developing the gifts and talents of all students. Phi Delta Kappan, v. 80, p. 1-15, 1998a.

RENZULLI, J. S. Renzulli Center for Creativity, Gifted Education, and Talent Development. 1998b. Disponível em: http://gifted.uconn.edu/schoolwide-enrichmentmodel/rising_tide/. Acesso em: 20 jul. 2016. 
RENZULLI, J. S.; REIS, S. M. The schoolwide enrichment model: a how-to guide for educational excellence. Connecticut: Creative Learning Press, 1997.

SATMAZ, Ismail; GENCEL, Ilke Evin. Identified So What?: Issues In: Education Of Gifted Individuals. Anais do ICCI EPOK 2018 - 6th International Congress on Curriculum and Instruction, Turquia, 2018, p. 724-725.

STEIN, Morris I. Stimulating Creativity. Individual/Procedures. New York: Academie Press, 1974.

VIRGOLIM, Angela Mágda Rodrigues. A contribuição dos instrumentos de investigação de Joseph Renzulli para a identificação de estudantes com Altas Habilidades/Superdotação. Revista Educação Especial, v. 27, n. 50, p. 581-610, 2014.

WECHSLER, Solange Muglia. Efeitos do treinamento em criatividade em crianças bem-dotadas e regulares. Arq. bras. Psic., Psicologia educacional e escolar, Rio de Janeiro, v. 4, p. 95-110, 1987.

WECHSLER, Solange Muglia. Criatividade: descobrindo e encorajando. São Paulo: Psy, 1998.

ZAVITOSKI, Pollyana. Superdotação e Criatividade: análise de dissertações e teses brasileiras. Dissertação (Mestrado). Universidade Estadual Paulista. Faculdade de Ciências, Bauru, 2015.

\section{Correspondência}

Taís Crema Remoli Ferreira - Universidade Estadual Paulista Júlio de Mesquita Filho. Rua: Av. Higino Muzi Filho, 737, Mirante. CEP: 17525-900. Marília, São Paulo, Brasil.

This work is licensed under a Creative Commons Attribution-NonCommercial 4.0 International (CC BY-NC 4.0) 